\title{
UNIVERSITY MANAGEMENT STIMULATING HIGHER EDUCATION QUALITY
}

\author{
Mariya Hristova \\ Todor Kableshkov University of Transport, Sofia, Bulgaria \\ Hristo Hristov \\ Todor Kableshkov University of Transport, Sofia, Bulgaria
}

\section{CMESTE}

JEL Category: I23, 128

\begin{abstract}
The quality of higher education has two aspects: 1. Quality of preparation of students as a result of received and acquired knowledge, skills, competencies and values; and 2. Quality of education objects - academic disciplines, teachers, majors. The article examines both aspects and focuses on two ideas: (1) The university Quality Management must coordinate the content and structure of the European and national qualification frameworks with the national accreditation systems and rating systems. Today this is not a fact. That way, students and doctoral students, teachers and academic leaders would generate aspirations and interests would form that are harmonious and synergistic to national and European requirements, mission, values and policies of the university. This would create prerequisites for better ranking in the national rating of universities which would come with the expected bonuses from the state budget for the University. (2) To generate motivation for high quality students, teachers and academic leaders by linking them with achievements of recognition and remuneration. This is possible only if there is an objective and recognized system of evaluation. It is proposed that the evaluation be multifactorial multi-subject, expert, quantitative (on a scale comparable to the national grading system) and is based on academic standards for the subject being assessed. The standards need to be harmonized with the National Qualifications Framework. To accomplish an objective student assessment, the article proposes the introduction of external evaluation and anonymous assessments from the written exam.
\end{abstract}

Keywords: Quality management, system, evaluation, maintenance, university, European Qualifications Framework, National Qualifications Framework, standard, assessment of university objects, quality improvement, stimulation of teachers and students

\section{INSTITUTIONALIZATION OF THE QUALITY OF EDUCATION IN EUROPE AND BULGARIA}

The European Higher Education Area (EHEA) is built on the principles and values set as early as in

Address of the corresponding author:

Mariya Hristova

䤵: mhristova@vtu.bg the Bologna Declaration in 1999 being enriched and approved in the years following it. One of these principles is the quality of higher education. 
Explicitly or implicitly, it was included in the agendas of periodic meetings of Ministers of Education of the countries-participants in the Bologna Process in Prague, Bergen, London, Leuven, Vienna, Budapest and Bucharest. As a result, the following decisions were made:

- European Qualifications Framework (EQF) (EC, 2008) in the EHEA, which serves as a basis to build national qualifications frameworks;

- General principles, criteria and methodology for quality assurance;

- Standards and guidelines for Quality Assurance in the European Educational Area

Three levels of implementation were introduced: institutional (internal-university), external (of the agencies for assessment and accreditation) and European, which is represented by the European Association for Quality Assurance in Higher Education (ENQA).

The European Parliament adopted an Agenda for the Modernisation of Europe's Higher Education Systems where it is underlined that "the quality and relevance of higher education are key conditions for extracting maximum benefit from the intellectual capital of Europe." (SEC(2011) 1063 final). It encouraged the institutions of higher education to develop and implement their own internal systems of quality management and accreditation agencies to apply the European standards and guidelines for quality assurance.

In compliance with the European Qualifications Framework, in 2012 the Council of Ministers approved the National Qualifications Framework of the Republic of Bulgaria (NQF) (2012), the last three levels of which define knowledge, skills and competencies general for all Bachelors, Masters and Doctors in Bulgaria. The National Evaluation and Accreditation Agency (NEAA) of the Republic of Bulgaria became a member of ENQA and is guided by its principles and standards. The Parliament adopted The strategy for the development of higher education in Bulgaria 2020 and Action Plan for its implementation.

Today Higher Education has a new philosophy. The future new model puts the personality of student, PhD student, postgraduate student in the centre of educational paradigms. It is a model where one has the right to choose what to study, where to study, whether and when to graduate but also he/she should take the responsibility of choice and decision. The man in a democratic and open society must prepare for successful professional and civic career on the dynamic national, European and world market. This model requires innovative educational policy oriented to diverse personal needs and multiple choices.

Nowadays the emphasis is placed on the model oriented to results where the revenues at universities correspond to the quality of educational services.

Since 2012 part of the state subsidy for higher education (currently only $4 \%$ is paid as a stimulus for universities with professional fields, which are top-rated in the Bulgarian University Ranking System (BURS) (IREG, 2013) of Ministry of Education and Science. This ranking system was created using European funds and includes criteria in several sections such as: accreditation evaluation, learning process, research, academic staff, learning environment, social life and administrative services, career of graduates and compliance with the labour market. Thus the government does not only declare its quality policy, but also begins to implement it through appropriate financial mechanisms.

To a large extent BURS repeats the criteria of NEAA. There is no consistency between the weights of evaluation criteria in both systems but it must be recognized that BURS is a step in the right direction. After the forthcoming imperative improvement of both systems and their harmonization they can become an effective tool for quality management in higher education on national level. Now changes in the Higher Education Act are also provided to increase the share of budgetary funding for quality assessed according to BURS.

One of the first steps in the adopted Action Plan was to make amendments to the Higher Education Act in February 2016. Performing its functions in education policies in compliance with the dynamics of social development, the government introduced priority professional fields and protected programmes, which there is social need of (not always those seeking higher education are not always aware of that): engineers, teachers, mathematicians, physicists, IT experts, agronomists, etc., and which are stimulatingly 
funded by a special order. The share of state subsidies for quality and performance is increased. For several years this share will cover the bulk of the state budget for maintenance of training: in 2016/ 2017 academic year it increases to $30 \%$ and in $2019 / 2020$ it will be $60 \%$.

Left without the needed state subsidies, universities will be forced to get rid of inefficient and uncompetitive academic structures and programmes, and vice versa, will develop others, which the country needs. Thus, adequate national quality policy could be implemented by statutory financial mechanisms, without power solutions and administrative measures. It remains to find out also efficient incentive mechanisms for prospective students to enrol in these programmes, which now seem to them difficult and unprofitable.

\section{UNIVERSITY QUALITY MANAGEMENT}

\subsection{Proposals}

The key ideas, which this paper advocates for, are related to university quality management. Two important steps are offered as efficient tools:

- To generate motivation for high quality effectively connecting the achievements of the academic staff and students with their recognition and remuneration.

- To coordinate the University Quality Management by contents and formally with the National Qualifications Framework, the national accreditation and ranking systems and BURS, which is not a fact now.

\subsection{Systems of evaluation and maintenance of quality in an university}

Within the context of the quality of education, the problem of university management acquires particular significance.

The mandatory System of Evaluation and Quality Assurance of Education was introduced by the Higher Education Act 10 years ago. As a consequence, all universities introduced their own systems of quality management, some of which being in compliance with the international ISO standards.
However, the analysis of the situation shows that a number of shortcomings in university quality management and the systems as part of it have not been overcome.

The process of evaluation and its results still remain rather formal and inefficient:

- Realistic self-evaluation has not become a common practice.

- There is a lack of interest of evaluators in the evaluation process.

- Small part of students participates fully in surveys on quality achieved.

- The evaluation is done within the university but the end user is outside of it.

- The importance of subjective factor is too high, which puts the adequacy of assessments into question.

- The publicity of evaluation is limited and does not create competition to achieve quality

The feedback between quality and its carrier - the teacher, student, academic leader - is open and practically "broken".

The Strategy of Higher Education states that low efficiency of the systems is largely due to the "lack of incentives for the best teachers." This "hinders promotion and fixes the traditions of equalization". Currently all teachers having one and the same academic rank receive one and the same salary, regardless of the work done, the complexity and quality of the creative product they produce. One of the main reasons for that is the lack of adequate and objective quality assessment.

To connect quality achievements with remuneration and recognition of teachers and academic authorities, it is necessary to objectively and adequately assess the results of their work and creativity.

Quality needs to form adequate incentives for students as well. Presumably students, especially those in master's degree courses, are "internally" motivated for knowledge and skills. But observations on university realities show that it applies to not more than $15-20 \%$ of the student community. Furthermore, under the current system of testing and evaluation it cannot be stated that the best students and those with the highest quality of training have achieved the highest results. At that, it is the numerical expression of success that scholarship incentives 
and some very tentative steps of universities towards "external" motivation depend on.

\subsection{Standards}

This paper starts from the definition that:

Quality is a complex multidimensional set of properties and characteristics of higher education (training of students) and its subjects (university, programme, syllabus, teacher) that give it ability to meet determined or suspected dynamically changing requirements to it (Hristova, 2007). Quality is as better as the difference between the dynamically changing requirements to the educational subject and the results is less as sooner this difference is overcome.

From this definition it appears that quality cannot be measured and assessed if there are no requirements defined to the relevant object and if there are no adequate measures.

The requirements for different educational degrees are included in the contents of the European Qualifications Framework (EQF) and National Qualifications Framework (NQF). They are standards of knowledge, skills and competences on EU and national levels but there are no requirements for the "output" of university and its programmes. They should be developed in compliance with the National Qualifications Framework.

The standard is a definition of the results to be achieved and the rules to be followed, which is formalized and approved by an authorized body (SEC(2011) 1063 final). According to the ENQA document "Standards and recommendations on quality assurance ..." it is not supposed to keep "strict implementation of the standard". Also, "it should not be interpreted as a prescription that can not be changed." (ENQA, 2015).

\subsection{Assessment and evaluators of university objects}

In world university practice there are different approaches and methods to assess the quality of training. Some of these rely on measuring outcomes; others rely on the difference between inlet and outlet of the "black box", which for these methods is the higher school.

It seems that "step by step "is the most appropriate approach. This approach is used to evaluated various aspects of training and research: teaching contents, organization and performance of learning process, teaching skill, school facilities, standards and requirements for evaluation of students, exam procedures, outcomes, themes and volume of research, involvement of teachers and students in research, quality of scientific results, etc. The aggregate value and significance of all these aspects determine quality. It is traced how all the steps in that process are performed and how it is controlled. If they are made in the best way, one can expect the best results.

This approach is conceptually similar to total quality control. It is also applied in ISO-standards. Once everything "inside" in the "white box" is made in the best way "creating" quality, there is no need of special attention to what is at the entrance, which is essential with other methods.

The method is applicable in the National Evaluation System in Bulgaria (NEAA). For example, 14 criteria are used for institutional accreditation, much more indicators and 127 assessments with maximum values of 0.2 to 4.0 in a 100-point interval scale. The method is also applied in BURS to determine ratings of professional fields at different universities:

To objectify assessments, evaluation is:

- Multi-factorial (Multi-criteria). Set of assessment factors and criteria directly related to the standards for the certain object; it covers and seals the concept of quality.

- Multi-subjective. There are minimum three different evaluating entities (parties) with different viewpoints. Those who have opposing interests are deliberately selected. They are usually grouped in users, selfassessment entities, and independent evaluators.

- Quantitative. Quantitative assessment is determination of the degree of approximation of "what is" to "what should be" (standard). Assessments are given for criteria and indicators in 100-point interval scale, as the maximum for each criterion and indicator is pre- defined that depends on its weight.

- Expert. No formal evaluation methods are looked for and proposed. There are no precise measures and formalizations with evaluating quality indicators both in the national evaluation system and the university one. It relies on the expertise of multi-subject. 
It is assumed that formal models cannot cover all sides and shades and are usually highly stylized. The mathematical relationships are rather questionable. That causes inexactness. Moreover, the evaluators are not responsible; they are not deeply involved in the evaluation process. It is why assessment should be expert by nature, based on direct and indirect impressions, personal experience and expertise on current and objective information from public and verified data of the university. The fulcrum of evaluation is presented by standards and requirements for assessments.

The multi-subjective evaluation requires evaluators with different interests: self-evaluation, users and independent experts.

Users include: employers who use university products: business entities, companies, public and social organizations; undergraduate and graduate students and when assessing a subject - fellow teachers in subjects chronologically following the one under evaluation.

Independent evaluators include industrial, professional and trade organizations (Union of Electrical Engineers, Chamber of Civil Engineers, Union of Scientists, Federation of Scientific Unions, Medical Association, Union of Economists, Union of Lawyers, etc.), editorial boards of journals, etc; former undergraduate and graduate students; Master degree students - for undergraduate courses; PhD students - for Master degree programmes.

\subsection{Criteria and indicators}

Quality is not a physical quantity and in strict metrological aspect it cannot be measured. Therefore, as stated above, different "viewpoints" are evaluated - quality criteria that can be assumed as analogous to physical quantities.

Criteria and indicators are developed for each of the evaluated objects. They have different significance, which is determined by specific weight coefficients or as percentage of the total evaluation. That is determined by the governing body - the one that "makes policy" of quality.

Criteria (indicators) for the quality of education are divisions of the criteria. The relationship between criteria and its performance is hierarchical. The criterion is a consolidated component of the complex (aggregated) assessment of quality and stands at the "entrance" of the process. The indicator is a component of the criterion summarizing the initial data of quality and "lies" at its "exit". The indicators do not contain quality explicitly, so evaluators are not tempted to be subjective, in particular to liberalize their assessments as in the case of direct quality assessment. This indirectness increases the reliability of assessments.

The assessment follows the principles, logics and mechanisms of programme accreditation in the national evaluation system. They have to be "transferred" and creatively transformed from professional fields to training programmes, subjects and teachers.

\subsection{Validation of assessments}

Assessments are probed on the university website before being proved (validated) to use. Anyone can make remarks and comments. Transparency and public awareness as factors for objectivity are relied on.

The validation of assessments is done according to an established way through faculty and university management bodies taking into account the comments on their publication. The results of the evaluation are processed electronically. The final estimates are published on the faculty website.

The evaluation of a teacher, subject or programme is an element of the non-formalized space where subjectivism cannot be overcome in principle. Objectification requires multi-factorial and multisubjective nature but they lead to complexity. When it is very complex, it might be inapplicable or inefficient. On the other hand, the lack of quantitative measures does not allow adequate stimulation of the teacher and leader. The problem of reasonable sufficiency is on optimization one. Nowadays electronic communication and processing made acceptable even more complex system.

\subsection{Assessment of students}

The assessment of student's success and achievements is the subject of research and internal university rules, often incorporated into the academic standards of courses and graduation.

The standards of assessing student's achievements should be defined in a way to 
objectify grades of students who should not crucially depend on the teacher, his preferences and personal attitude. They should be irrelevant to his personality.

A sample formalization of standards for evaluation could be:

- Excellent - very good knowledge of information sources, thoroughly mastered key and additional knowledge and skills, meaningful and proper understanding of the subject issues, skills to solve complex problems, own thinking and reasoning of decisions.

- Very good - for well-acquired key and additional knowledge, meaningful and proper understanding of the subject issue, skills to apply knowledge to complex case studies and problems.

- Good - for acquisition of key and additional knowledge to solve case studies and problems without being mandatory to reach independent thinking and creativity.

- Satisfactory - for acquisition of key knowledge and solutions of simple problems.

- Failed - if it meets none of the requirements given above.

The final grade determines to what the extent the student has achieved the aim of teaching a given course, module or another element of educational activity. It should be multicomponent. Besides a written exam (in the prevailing case), the final grade should include the student's work and achievements during the semester, assessment of his/her interaction with the teacher, including research and projects.

Within the effort to objectify grades, here it is proposed to introduce external evaluation and anonymous assessment of the written exam. The external evaluation should be independent of the subject holder, controlled by the management body (e.g. Faculty Council). External assessors should be professors from leading universities, possibly foreign, as well as eminent professionals (possibly with $\mathrm{PhD}$ degrees) from advanced business and public practice. This century-old practice of the United Kingdom has given good results in some Bulgarian universities recently: both for objectifying assessments and harmonization with business needs and requirements of the national and European standards.

The annual grade that serves to stimulate the student for quality of his/her training and academic achievements should be linked to the credits of subjects $g_{1}, g_{2}, g_{3}, \ldots g_{n}$ according to the curriculum. It should be calculated as a weighted average of all grades $x_{1}, x_{2}, x_{3}, \ldots x_{n}$ throughout the school year by applying the following formula (1):

$m=\frac{\sum_{i} x_{i} g_{i}}{\sum_{i} g_{i}}=\frac{x_{1} \cdot g_{1}+x_{2} \cdot g_{2}+\cdots+x_{n} \cdot g_{n}}{g_{1}+g_{2}+\cdots+g_{n}}$

Thus the annual success rate of each student is objectified taking into account also the structure of his/her knowledge and skills and their importance.

\subsection{Harmonization and comparative analysis of evaluation systems and standards on different levels}

The European Qualifications Framework (EQF) is a standard of the European Higher Education Area (EHEA) related to what a graduate, holder of the respective degree, must know, understand and what can do. Adopting the EQF, the European institutions have committed to the unity of requirements, which each country of the EHEA should strive to. It is a tool that aims to make qualifications and education systems in different countries of the community more easily recognizable and comparable. The EQF facilitates the mutual recognition and it is important for learners and employers. It promotes mobility of students and $\mathrm{PhD}$ students to an extent comparable or higher than through the European Credit Transfer System (ECTS).

Currently education in the EEA member countries should be brought in compliance with the European standards ensuring equivalence of degrees and harmonized with the NQF, which presumably is harmonized with the EQF (framework standards). However, the high level of abstraction, which the EQF and NQF are necessarily written on (to be generally valid), does not allow to directly use them for development of educational content. To decrypt and specify knowledge, skills, values and professional qualifications arising from the framework standards for each programme, it is necessary to apply intellectual effort in the presence of high professional competence in this programme. 
To achieve confidence that knowledge, skills, values and professional qualifications have been acquired, they should be "implanted" in the curriculum and verified at testing and graduation of students. Upon accreditation of a professional field, they should be checked on validity. Otherwise these framework standards will remain only good wishes. Currently that is not a fact. They are absent in the NEAA criteria and academic quality systems.

The internal evaluation of programmes at the university shall be made according to criteria, rules and mechanisms arising from the NEAA and BURS criteria and in similar numerical scale. It is necessary to avoid divergence and focus the efforts of academic staff and students on activities and areas recognized as important and valuable in the stage of development. Thus it is possible to obtain better chances for top ranking of the respective university in BURS, which is financially rewarded by the state.

The positive differences from the evaluation system of NEAA and to a bigger extent from rating offered by BURS are as follows:

- academic standards as reference points for quality assessment, which do not exist in national evaluation systems;

- including users and independent evaluators in assessment, which cannot be said about NEAA despite some positive steps in that direction;

- development of rules and mechanisms (some of them being offered in this paper) to overcome subjectivity in evaluation, which is too strong in accreditation.

At the same time there are significant differences between national rules and university standards. Here are some of them:

1. National criteria refer to all types of universities in Bulgaria without considering their missions, visions, values and goals. This makes these criteria sufficiently abstract and general. University quality criteria, hence academic standards as a basis of quality assessment have to meet the peculiarities and requirements of the respective university.

2. Under the conditions of competition on the intellectual market, each university looks for its niche, opportunities to unfold its strengths, which brings meaningful specificity both in standards and their implementation. Best universities can afford higher standards that meet the interests of well-trained, motivated and talented students.

\section{QUALITY IMPROVEMENT}

\subsection{Stimulation of teachers and leaders}

Stimuli have moral and material expression.

The recognition of academic teachers as scientists, their aspiration for promotion and getting professorship, are deeply embedded values in everyone with academic career. That is why he/she is sensitive to injustice in evaluation and has a right to respond when being undervalued. It is a sign of his professional honour and teaching dignity which affects significantly on his/her motivation at the university and ultimately on the quality of his/her product. Therefore, the establishment and proper functioning of quality assessment systems and university management of teacher's motivation are so much important.

Quality management systems should motivate teachers. They should close the feedback: evaluation of the achieved quality, reward for those who achieve quality, quality improvement, evaluation, etc. They should offer personalized treatment to the teacher removing proven contraindication equalization of remuneration for one and the same position.

Of course, justice requires also adequate money equivalent. It does not concern separate and sporadic awards but systematic link of financing with the final results of everyone's work. The system of quality management only submits its evaluation in a 100- degree scale.

The existing situation when all at one and the same academic position receive one and the same salary despite the difference in quality of results and quantity of their creative work, which is very different, sometimes measured in times, creates a sense of injustice. That is the moral ground for demotivation of many of the academic staff who do not get recognition they deserve. It does not create the competitive behaviour, which is characteristic of the world we now live in.

It is possible to suggest a formal model used to obtain a quantitative measure for appropriate 
remuneration. Besides the academic position that a person occupies at university, the scientific degree that one has acquired, the academic load, measured by the standards of academic employment, the model must take into account the quality of education and research. An important factor supporting this thesis is that, through the budget, the government stimulates quality as determined by the established ranking system. Since it operates on national level and after changing the Higher Education Act in early 2016, which strengthened the significance of this factor, it must be applied to evaluate teachers at the university carried out by the same approach. Thus the approach is transferred from professional fields to the person at the university already appreciated by an objectified university system of quality management. A unified system "from top to bottom" is created.

\subsection{Stimulation of students}

The grades in the preceding year derived as an average of semester exams are used in all initiatives to reward students for their success. But they have questionable objectivity.

It is also proposed to discuss the idea of a global stimulating system.

It understands that students pay full tuition for their education determined by the university itself. However, this money is not their own but money of the government, which so far have been provided to universities as budget subsidies. Money is given to students as vouchers in a certain order (including competitions). Students "carry" funds for their education at the higher school where they have decided to study. It is against a contract with the government for a credit, which might not be returned under certain conditions. A regulator of returning the loan is introduced, the fundamentals of which are:

- If the student works abroad after the graduation, he/she returns the credit for a certain period.

- The one who work in Bulgaria, pays back the loan after the grace period: completely or partially depending on his/her achievements and successful career in the field of study.

- The government absolves loans to students with highest results.
The model is developed under the conditions of balanced regulation

The total state subsidy for education, which is a component of the state budget for higher education, is provided in the form of vouchers according to government priorities, which regulates public interest through. The government promotes targeted training in priority professional fields and protected fields of national importance announcing more vouchers and more favourable contract terms with the student.

The right of universities to determine their own tuition fees increases their autonomy, fixed in Art. 53 of the Bulgarian Constitution, and makes the market real. The created free exchange generates competition of applicants and of universities.

The system of loan returning compels students to carefully select their programmes as they think economically motivated for their future career (now it is now a fact). Since the student is going to work in his/her professional field, one will make efforts to improve one's training. Now he/she will exert pressure on teachers to get advanced knowledge and applicable skills. The share of students who study at the government expense to get a "diploma" and in unwanted programmes without intent to work in the corresponding fields will decrease.

This model creates levers of management and implementation of the state policy. The model is economically viable for the budget because the loans given to students whose career is not in the field of their studies or have gone abroad as well as part of the loans given to students without high grades are returned to the state budget.

\section{CONCLUSION}

The paper proposes models to evaluate teachers for quality results. On this evaluation basis a stimulating system for academic staff is offered, through which the university personalize its attitude to every teacher.

The approaches and principles, which are suggested, guarantee the objectivity of evaluation, which is not closed within the university but also involves the users of the university product. To implement such a system, it should not raise serious objections. There should be general agreement and recognition. The assessments 
should be public at least within the university and the incentives for those who have achieved quality should from be derived from the assessments.

The coordination of systems for evaluation on European, national and university levels will result in a single system of university management, being in its nature from "top" to "bottom", that:

1. Transfers the principles, methods and mechanisms of the national evaluation system from the national level to university one, while improving them;

2. Directs aspirations and forms interests harmonious and synergistic to the NQF, mission, values and policies of higher education;

3. Creates prerequisites for better ranking in the national ranking system of professional fields with consequent budget bonuses for the university;

4. Motivates students to study more and participate in evaluation because it already depends on them a lot and they can see that.
5. Solves the problems of relationships with users who become part of the system.

6. Due to the feedback between quality and remuneration the system can self-improve and enhance its adequacy and efficiency

Such university management that stimulates quality can be expected to have effects associated with a complete change in the atmosphere of university. Redistribution of funding to leading university teachers and leaders could occur and over time it could cause natural selection of academic staff in favour of quality. The joint evaluation activity will inevitably bring universities and businesses nearer and the gap between them will start to close.

The system has ability of self-improvement thanks to the strong feedback. Shortcomings, gaps and weaknesses in the evaluation criteria and mechanisms would violate the interests of teachers and leaders and will cause timely adjustments.

\section{WORKS CITED}

EC. (2008). The European Qualifications Framework for Lifelong Learning (EQF). doi:10.2766/14352

ENQA. (2015). Standards and Guidelines for Quality Assurance in the European Higher Education Area (ESG). Retrieved from European Association for Quality Assurance in Higher Education (ENQA): http://www.enqa.eu/wp-content/uploads/2015/11/ESG_2015.pdf

Hristova, M. (2007). Quantitative Methods for Evaluation and Quality Management of Education in the Universities - dissertations for degree "doctor". Sofia.

IREG. (2013). Bulgarian University Ranking System. Retrieved from IREG Observatory on Academic Ranking and Ecellence: http://ireg-observatory.org/en/index.php/rankingprofile? ranking $=32 \&$ view=application

Natsionalna kvalifikatsionna ramka na Republika Bulgariya. (2012, Feb 02). Retrieved from Ministerski savet - Portal na obstetstveni konsultacii: http://www.strategy.bg/StrategicDocuments/View.aspx?lang=bg-BG\&ld=719

SEC(2011) 1063 final. (2011, 09 20). Communication from the Commission to the European Parliament, the Council, The European Economic and Social Committee and the Committee of the Regions - Supporting growth and jobs - an agenda for the modernisation of Europe's higher education systems. Retrieved from European Commission: http://eur-lex.europa.eu/legalcontent/EN/TXT/PDF/?uri=CELEX:52011DC0567\&from=EN

Received for publication: Revision received:

Accepted for publication:
29.03.2016

16.05 .2016

10.06.2016 


\section{How to cite this article?}

Style - APA Sixth Edition:

Hristova, M., \& Hristov, H. (2016, July 15). University management stimulating higher education quality. (Z. Čekerevac, Ed.) MEST Journal, 4(2), 103-112. doi:10.12709/mest.04.04.02.11

Style - Chicago Sixteenth Edition:

Hristova, Mariya, and Hristo Hristov. 2016. "University management stimulating higher education quality." Edited by Zoran Čekerevac. MEST Journal (MESTE) 4 (2): 103-112. doi:10.12709/mest.04.04.02.11.

Style - GOST Name Sort:

Hristova Mariya and Hristov Hristo University management stimulating higher education quality [Journal] // MEST Journal / ed. Čekerevac Zoran. - Belgrade : MESTE, July 15, 2016. - 2 : Vol. 4. - pp. 103-112.

Style - Harvard Anglia:

Hristova, M. \& Hristov, H., 2016. University management stimulating higher education quality. MEST Journal, 15 July, 4(2), pp. 103-112.

Style - ISO 690 Numerical Reference:

University management stimulating higher education quality. Hristova, Mariya and Hristov, Hristo. [ed.] Zoran Čekerevac. 2, Belgrade : MESTE, July 15, 2016, MEST Journal, Vol. 4, pp. 103-112. 